\title{
Voluntary Exercise and Sucrose Consumption Enhance Cannabinoid CBI Receptor Sensitivity in the Striatum
}

\author{
Valentina De Chiara ${ }^{1,2,6}$, Francesco Errico ${ }^{3,6}$, Alessandra Musella ${ }^{1,2}$, Silvia Rossi ${ }^{1,2}$, Giorgia Mataluni ${ }^{1,2}$, \\ Lucia Sacchetti $^{4}$, Alberto Siracusano ${ }^{4}$, Maura Castelli ${ }^{1,2}$, Francesca Cavasinni ${ }^{1,2}$, Giorgio Bernardi ${ }^{1,2}$, \\ Alessandro Usiello ${ }^{3,5}$ and Diego Centonze*,1,2 \\ 'Clinica Neurologica, Dipartimento di Neuroscienze, Università Tor Vergata, Rome, Italy; ${ }^{2}$ Fondazione Santa Lucia/Centro Europeo per la Ricerca \\ sul Cervello (CERC), Rome, Italy; ${ }^{3}$ Behavioural Neuroscience Laboratory, CEINGE_Biotecnologie Avanzate, Naples, Italy; ${ }^{4}$ Clinica Psichiatrica, \\ Dipartimento di Neuroscienze, Università Tor Vergata, Rome, Italy; ${ }^{5}$ Department of Health Science, Università del Molise, Campobasso, Italy
}

\begin{abstract}
The endogenous cannabinoid system is involved in the regulation of the central reward pathway. Running wheel and sucrose consumption have rewarding and reinforcing properties in rodents, and share many neurochemical and behavioral characteristics with drug addiction. In this study, we investigated whether running wheel or sucrose consumption altered the sensitivity of striatal synapses to the activation of cannabinoid CBI receptors. We found that cannabinoid CBI receptor-mediated presynaptic control of striatal inhibitory postsynaptic currents was remarkably potentiated after these environmental manipulations. In contrast, the sensitivity of glutamate synapses to $C B I$ receptor stimulation was unaltered, as well as that of GABA synapses to the stimulation of presynaptic GABAB receptors. The sensitization of cannabinoid $\mathrm{CBI}$ receptor-mediated responses was slowly reversible after the discontinuation of running wheel or sucrose consumption, and was also detectable following the mobilization of endocannabinoids by metabotropic glutamate receptor 5 stimulation. Finally, we found that the upregulation of cannabinoid transmission induced by wheel running or sucrose had a crucial role in the protective effects of these environmental manipulations against the motor and synaptic consequences of stress. Neuropsychopharmacology (2010) 35, 374-387; doi:I0.1038/npp.2009.14I; published online 23 September 2009
\end{abstract}

Keywords: dopamine; endocannabinoids; IPSC; mGlu 5 receptors; reward; stress

\section{INTRODUCTION}

Studies with drugs of abuse suggested that cannabinoid receptors are involved in the regulation of the central reward system. Accordingly, inactivation of cannabinoid CB1 receptors attenuates the rewarding effects of cannabinoids (Ledent et al, 1999), opiates (Ledent et al, 1999; Martin et al, 2000; Cossu et al, 2001), and cocaine (Chaperon et al, 1998), whereas stimulation of these receptors elicits relapse not only to cannabinoid consumption but also to cocaine, heroin, alcohol, and methamphetamine (Fattore et al, 2007; Higuera-Matas et al, 2008).

We have recently reported that cocaine-induced conditioned place preference (CPP) is associated with hypersensitivity of striatal GABA synapses to the stimulation of cannabinoid CB1 receptors (Centonze et al, 2007a). This finding raises the possibility that other forms of reward-based behaviors may rely on the sensitization of

*Correspondence: Dr D Centonze, Dipartimento di Neuroscienze, Università Tor Vergata, via Montpellier I, Rome 00 I33, Italy, Tel: + 39 067259 60 I0, Fax: + 39067259 6006, E-mail: centonze@uniroma2.it ${ }^{6}$ These authors contributed equally to this work.

Received I 8 March 2009; revised 21 July 2009; accepted 10 August 2009 cannabinoid $\mathrm{CB} 1$ receptor-mediated transmission in this brain area. Running wheel activity has strong rewarding and reinforcing properties in rodents, and shares many neurochemical and behavioral characteristics with druginduced reward situations, through the modulation of striatal neuron activity (Werme et al, 2000, 2002; Lett et al, 2001; de Visser et al, 2007). It is therefore conceivable that this environmental manipulation mimics the effects of cocaine on cannabinoid-mediated control of striatal synaptic transmission and, in support of this hypothesis, it has been reported that voluntary running wheel exercise activates striatal dopamine (DA) signaling (El Rawas et al, 2009), and increases some behavioral and metabolic effects of cannabinoid CB1 receptor blockade (Zhou and Shearman, 2004).

Sweet foods and drinks also have intense rewarding properties (Lenoir et al, 2007), and many commonalities exist between overconsumption of sugars and drug addiction (Levine et al, 2003; Kelley, 2004; Volkow and Wise, 2005). Accordingly, both sweet tastants (Mark et al, 1991; Hajnal et al, 2004) and drugs of abuse (Di Chiara and Imperato, 1988; Pontieri et al, 1996) stimulate DA signaling in the striatum, and both cross-tolerance (Lieblich et al, 1983; d'Anci et al, 1996) and cross-dependence (Rudski et al, 1997; Kanarek et al, 1997; Colantuoni et al, 2004) have 
been observed between sugars and drugs of abuse. Furthermore, the endocannabinoid system has a key role in the rewarding properties of palatable foods (Cota et al, 2003; Mahler et al, 2007), and cannabinoid CB1 receptor blockade decreases motivation for sweet foods, whereas activation of these receptors increases it (Simiand et al, 1998; Cota et al, 2003; Ward and Dykstra, 2005; Mahler et al, 2007).

Thus, aim of this study was to assess cannabinoidmediated transmission in the striatum after running wheel and sucrose consumption. Our results show that both environmental manipulations potentially associated with reward sensitize cannabinoid CB1-mediated transmission in the striatum. The described upregulation of cannabinoid transmission appears a crucial event for the protective effects of voluntary exercise and sucrose against the synaptic and motor consequences of stress.

\section{MATERIALS AND METHODS}

Male C57/bl6 mice (6 weeks old at the beginning of running wheel or sucrose exposition) were used for all the experiments. All animals were housed, four per cage with food and water ad libitum, on a 12-h light/dark cycle with lights on at 0600 hours and controlled $\left(22-23^{\circ} \mathrm{C}\right)$ temperature. Mice were individually housed in the experiments described in Figure 3, where the rewarding properties of sucrose on single animals were evaluated. All efforts were made to minimize animal suffering and to reduce their number, in accordance with the European Community Council Directive of 24 November 1986 (86/609/EEC).

Mice were randomly allocated in the control, running wheel, or sucrose groups. For each experimental group, a numerically comparable group of control animals was constituted by age-matched mice never exposed to running wheel and drinking normal water. In a further set of experiments, neurophysiological recordings were obtained from mice reared in cages equipped with a wheel with blocked movement.

\section{Electrophysiology}

To study the effects of voluntary exercise, mice were housed in a cage equipped with a running wheel for $1,3,7,15$, or 30 days. Another group of mice was reared in control cages and were allowed to consume ad libitum a drinking fluid containing sucrose ( $3 \%$ in tap water) for $1,3,7$, or 15 days. In some mice exposed for 7 days to sucrose, sucrosecontaining solution was replaced with normal water for 1, 3, or 7 days before the electrophysiological experiments. Furthermore, in some mice exposed for 15 days to running wheel, the enriched cage was replaced with a normal one for 1,3 , or 7 days before the electrophysiological experiments.

Whole-cell patch clamp recordings from single striatal neurons in corticostriatal coronal slices $(200 \mu \mathrm{m})$ were carried out as previously described (Centonze et al, 2005; 2007a,b; Rossi et al, 2008). To detect evoked inhibitory postsynaptic currents (eIPSCs), spontaneous IPSCs (sIPSCs), and miniature GABAA-mediated IPSCs (mIPSCs), intraelectrode solution had the following composition $(\mathrm{mM}): \mathrm{CsCl}(110), \mathrm{K}^{+}$-gluconate (30), ethylene glycol- bis( $\beta$-aminoethyl ether)- $N, N, N^{\prime}, N^{\prime}$-tetra-acetic acid (EGTA; 1.1), HEPES ( $N$-(2-hydroxyethyl)-piperazine- $N^{\prime}$-ethanesulfonic acid; 10), $\mathrm{CaCl}_{2}$ (0.1), Mg-ATP (4), and Na-GTP (0.3). MK-801 $(30 \mu \mathrm{M})$ and CNQX $(10 \mu \mathrm{M})$ were added to the external solution to block, respectively, NMDA and nonNMDA glutamate receptors. Conversely, to study spontaneous glutamate-mediated excitatory postsynaptic currents (sEPSCs), the recording pipettes were filled with internal solution of the following composition: $(\mathrm{mM}) \mathrm{K}^{+}$-gluconate (125), $\mathrm{NaCl}$ (10), $\mathrm{CaCl}_{2}$ (1.0), $\mathrm{MgCl}_{2}$ (2.0), 1,2-bis (2-aminophenoxy) ethane- $N, N, N^{\prime}, N^{\prime}$-tetra-acetic acid (BAPTA; 0.5), HEPES (19), guanosine triphosphate (GTP; 0.3), Mgadenosine triphosphate (Mg-ATP; 1.0 ), adjusted to $\mathrm{pH} 7.3$ with $\mathrm{KOH}$. Bicuculline $(10 \mu \mathrm{M})$ was added to the perfusing solution to block GABAA-mediated transmission. The detection threshold of sIPSCs, mIPSCs, or sEPSCs was set at twice the baseline noise. The fact that no false events would be identified was confirmed by visual inspection for each experiment. Offline analysis was carried out on spontaneous and miniature synaptic events recorded during fixed time epochs (5-10 samplings of 2-3 min duration each, recorded every 2-3 $\mathrm{min}$ ), for a total of $10-30 \mathrm{~min}$ analysis for each recorded neuron, depending on the length of the experiment. Only cells that showed stable frequencies in control ( $<20 \%$ changes during the control samplings) were taken into account. The rare events with complex peaks were eliminated, because amplitudes of the single synaptic currents composing these events were difficult to determine.

Evoked IPSCs were elicited at $0.1 \mathrm{~Hz}$ frequency using bipolar electrodes located within the striatum. pCLAMP 9 was used to store the data. In distinct neurons, eIPSCs of similar amplitude were obtained with variable intensities of stimulation, mainly depending on the distance between the stimulating and recording sites. The amplitude of eIPSCs normally ranged between 30 and 200 pA.

Mice were killed for the electrophysiological evaluations immediately after exposure to running wheel or to sucrose. In other experiments, $24 \mathrm{~h}$ was the time interval between the last session of stress and the electrophysiological recordings.

\section{Sucrose Preference}

The test was performed as previously described (Sonnier et al, 2007). Male C57/bl6 mice ( $n=11$ per sucrose concentration), placed in individual cages 2 weeks before the test, were submitted to a water vs sucrose two-bottle preference test. Increasing sucrose solutions were used (0.75 and 3\%). Each concentration was presented in consecutive 2-day blocks. The solutions were available $23 \mathrm{~h}$ per day. During the remaining $1 \mathrm{~h}$, the volumes consumed were measured and the bottles refilled. The left-right positions of the sucrose and water were alternated for each concentration (to control for the preference of some mice for a particular side). Total intakes (in $\mathrm{ml}$ ) were averaged. Preference for sucrose (\%) was calculated as the milliliter of sucrose solution drank over the total drink intake (eg, [sucrose/sucrose + water] $\times 100)$. Significance was calculated by one-way ANOVA (sucrose concentration effect), followed by Fisher's post-hoc analysis. 


\section{Psychoemotional Stress and Behavior}

Psychoemotional stress was induced as already described (Avgustinovich et al, 2005; Berton et al, 2006; Rossi et al, 2008). Control $(n=12)$ or previously rewarded mice exposed to running wheel ( 15 days, $n=10$ ) or to sucrose (7 days, $n=10$ ) were subjected to daily bouts for $10 \mathrm{~min}$ with an aggressive CD1 resident mouse, followed by 3-h protected sensory contact with their aggressor. Mice were exposed to a different aggressor each day for 3 days. This protocol of stress has been recently shown to cause a marked downregulation of cannabinoid CB1 receptors controlling GABA transmission in the striatum (Rossi et al, 2008).

At $24 \mathrm{~h}$ after the last event of sensory aggression, mice were subjected to the open-field test to compare their motor responses with those of control (not stressed and standardhoused) animals $(n=13)$. Motor response was also addressed in the open-field in rewarded (15 days running wheel $(n=9)$ and 7 days sucrose $(n=9))$, not stressed mice.

The open-field paradigm assesses motor activity of animals in an averse, stressful environment. This protocol was carried out as previously reported (Errico et al, 2008). Briefly, mice were placed into the center of a clear Plexiglas arena $(25 \mathrm{~cm} \times 35 \mathrm{~cm} \times 20 \mathrm{~cm})$ in which they were allowed to explore for $30 \mathrm{~min}$. Overhead incandescent light bulbs provided a 600 lux illumination inside the test chamber. Total and center distance were recorded using a video tracking system (Videotrack, Viewpoint S.A., Champagne au Mont d'Or, France). Center distance was divided by the total distance to obtain a center/total distance ratio used as an index of anxiety-related behavior.

\section{Statistical Analysis}

Throughout the text, ' $n$ ' refers to the number of cells, unless otherwise specified. One to six neurons per animal were recorded. Each electrophysiological measure in each group of mice was obtained by pooling data from at least six different animals. For data presented as the mean \pm s.e.m., statistical analysis between two groups was carried out using a paired or unpaired Student's $t$-test or Wilcoxon's test. Multiple comparisons were analyzed by one-way or two-way ANOVA followed by appropriate post-hoc comparisons (Tukey HSD or Student's $t$-test). The significance level was established at $P<0.05$. To determine differences between two cumulative distributions, the KolmogorovSmirnov test was used.

\section{Drugs}

Intraperitoneal AM251 (6 mg/kg, in saline with DMSO 10\% and Tween $80.5 \%$ ) was administered daily in mice preexposed to running wheel (15 days) or to sucrose ( 7 days) during the 3-day stress procedure. Mice receiving an equal number of intraperitoneal injections of vehicle were used as controls.

Drugs used in slices for the electrophysiological experiments were first dissolved in DMSO (AM251, HU210) or in water, then in the bathing ACSF to the desired final concentration. DMSO was used when appropriate in control experiments. The concentrations of the various drugs were chosen according to previous in vitro studies on corticostriatal brain slices (Centonze et al, 2007a,b; Rossi et al, 2008), and were as follows: AM251 $(10 \mu \mathrm{M})$, baclofen ( 3 and $10 \mu \mathrm{M})$, CNQX $(10 \mu \mathrm{M}), 3,5-\mathrm{DHPG}$ (DHPG, $50 \mu \mathrm{M})$, HU210 $(0.1,0.3 \mu \mathrm{M}, 1 \mu \mathrm{M}$, and $3 \mu \mathrm{M})$, MK-801 $(30 \mu \mathrm{M})$, tetrodotoxin (TTX, $1 \mu \mathrm{M})$ (from Tocris, Bristol, UK). Bicuculline $(10 \mu \mathrm{M})$ (from Sigma-RBI, St Louis, MO, USA). Unless otherwise specified, HU210 was applied at the concentration of $1 \mu \mathrm{M}$.

\section{RESULTS}

\section{Effects of HU210 on GABA Transmission in Mice Exposed to Running Wheel or Sucrose}

Application of the cannabinoid CB1 receptor agonist HU210 $(10 \mathrm{~min})$ significantly reduced the frequency of striatal sIPSCs in control mice $(n=10, p<0.01$ compared with predrug values). The selective antagonist of CB1 receptors AM251 prevented this effect $(n=7, p>0.05$ compared with pre-drug values). In striatal neurons from mice exposed to sucrose-containing solution for 1 and 3 days or to running wheel for 1, 3, and 7 days, HU210 produced similar effects to their respective controls ( $n=$ at least $8, p>0.05$ with respect to controls for each time point). Conversely, in neurons from mice exposed to a more prolonged potentially rewarding paradigm (7 and 15 days for sucrose-containing solution; 15 and 30 days for running wheel), HU210 effects were remarkably potentiated $(n=$ at least $14, p<0.01$ compared with controls for each time point and both experimental groups), indicating increased sensitivity of GABA synapses to cannabinoid receptor stimulation (Figure 1a and c). Statistical analysis carried out by taking the mean of the data from single animals confirmed these results (control mice $(n=8): 80 \pm 3 \%$; sucrose-exposed mice $(n=8): 54 \pm 4 \%$; and running wheel-exposed mice $(n=9): 51 \pm 5 \% ; p<0.05)$.

In striatal neurons from control mice, as well as from mice exposed for 7 consecutive days to sucrose-containing solution or for 15 consecutive days to running wheel, HU210 effects were prevented by pre-incubating (5-10 $\mathrm{min})$ the slices with AM251, antagonist of CB1 receptors $(n=6$ and $p>0.05$ for each group) (Figure $1 \mathrm{~b}$ and $\mathrm{d}$ ). In these experiments, AM251 was unable to alter per se the frequency of sIPSCs ( $p>0.05$ for the three groups) (data not shown).

To isolate synaptic GABA events from the possible contamination of pre- and postsynaptic spiking activity, miniature GABAergic currents (mIPSCs) were recorded after the application of TTX (5-10 min), a selective voltagedependent sodium channel blocker. As described, mean frequency of mIPSCs was significantly lower compared with that of sIPSCs recorded from control neurons and from neurons exposed for 15 days to running wheel or for 7 days to sucrose ( $n=$ at least 12 and $p<0.05$ with respect to predrug values for each experimental group), whereas mean amplitude was unchanged ( $n=$ at least $11, p>0.05)$. Furthermore, no differences were evident between mIPSC frequencies and amplitudes recorded in control, running wheel-, or sucrose-receiving animals $(n=$ at least 12, $p>0.05$ for both parameters) (data not shown).

We investigated the electrophysiological effects of HU210 on mIPSCs recorded from control mice and in mice exposed 


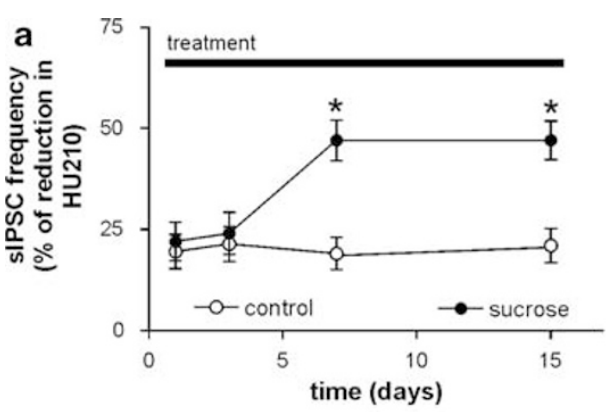

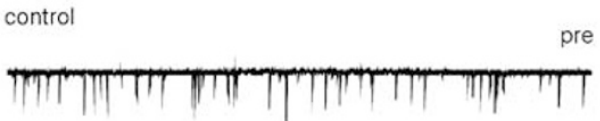

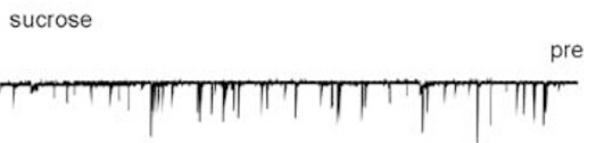

C

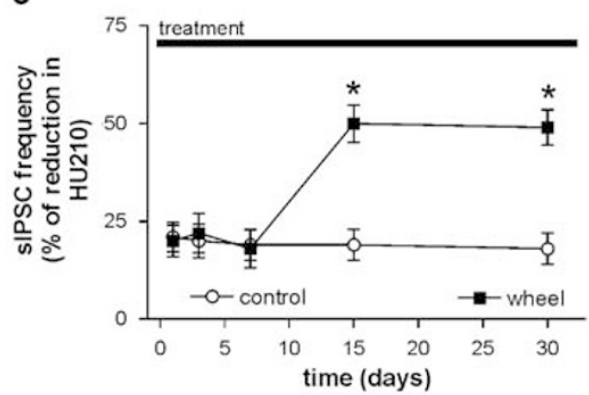

control

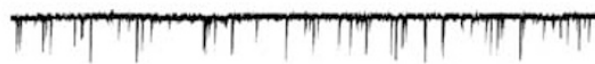

wheel

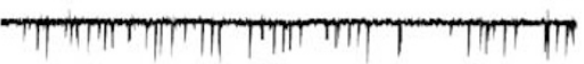

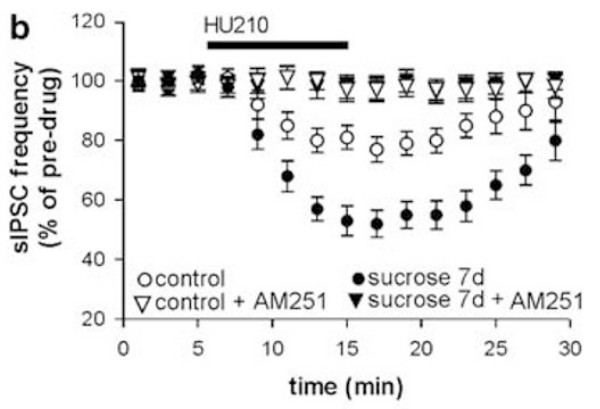

HU210

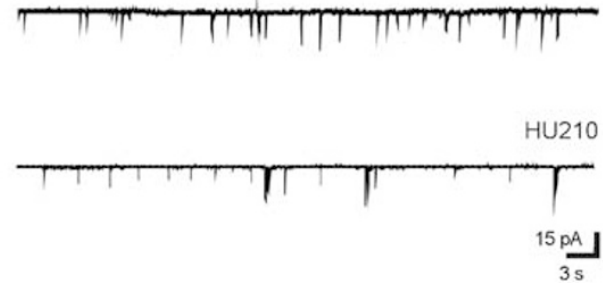

d

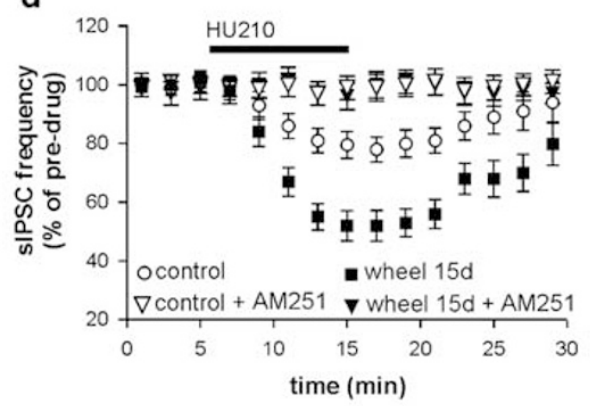

HU210
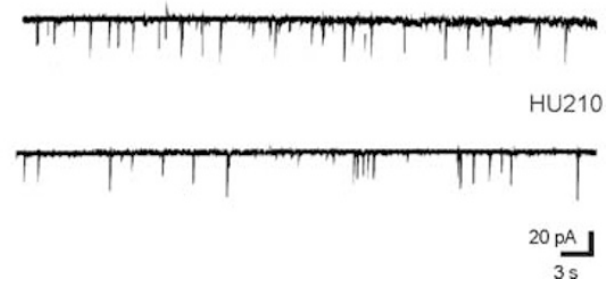

Figure I Running wheel and sucrose consumption potentiate the effects of HU2IO on striatal sIPSCs. (a) The graph shows that HU2I0-induced reduction of sIPSC frequency was normal after I and 3 days of exposure to sucrose-containing solution. Conversely, the effects of HU2 I0 on sIPSCs were potentiated after 7 and 15 days of sucrose exposure. (b) Preincubation with the CBI receptor antagonist AM25I prevented the depressant action of $\mathrm{HU} 2 \mathrm{I} O$ both in control mice and in sucrose-exposed mice. The electrophysiological traces in the bottom are examples of voltage-clamp recordings before and during the application of HU2IO in control and sucrose (7 days)-exposed mice. (c) The graph shows that the HU2I0-induced reduction on sIPSC frequency was normal after I, 3, and 7 days of wheel running. Instead, the effects of HU2 I 0 on sIPSCs were potentiated after I 5 and 30 days of exposure to running wheel. (d) Preincubation with AM25I prevented the depressant action of HU2IO in both control mice and running wheel-exposed mice. The electrophysiological traces on the bottom are examples of voltage-clamp recordings before and during the application of HU2I0 in control and running wheel ( 15 days)-exposed mice. $*$ p $<0.05$ compared with control.

to running wheel for 15 days or to sucrose for 7 days. In line with our results on sIPSCs, bath application of HU210 significantly reduced mIPSC frequency $(n=$ at least 14 and $p<0.01$ for each group) but not amplitude $(p>0.05)$ in all the tested neurons. In slices from mice exposed to running wheel and to sucrose, the inhibitory effects of HU210 on mIPSC frequency were significantly greater $(p<0.01$ with respect to controls) (Figure $2 \mathrm{a}-\mathrm{e}$ ). Statistical analysis carried out by taking the mean of the data from single animals confirmed the effects of HU210 on mIPSC frequency (control mice $(n=7): 82 \pm 3 \%$; sucrose-exposed mice $(n=8): 57 \pm 4 \%$; and running wheel-exposed mice $(n=8): 55 \pm 5 \% ; p<0.05)$.

To further confirm that the effects of cannabinoid receptor stimulation on striatal GABA transmission were presynaptic, we also measured the action of HU210 on paired pulse ratio (PPR) of eIPSCs $(70 \mathrm{~ms}$ interstimulus interval). In control, running wheel (15 days)-, and sucrose (7 days)-exposed mice ( $n=6$ for each group), the depressant effect of HU210 on eIPSCs was associated with 

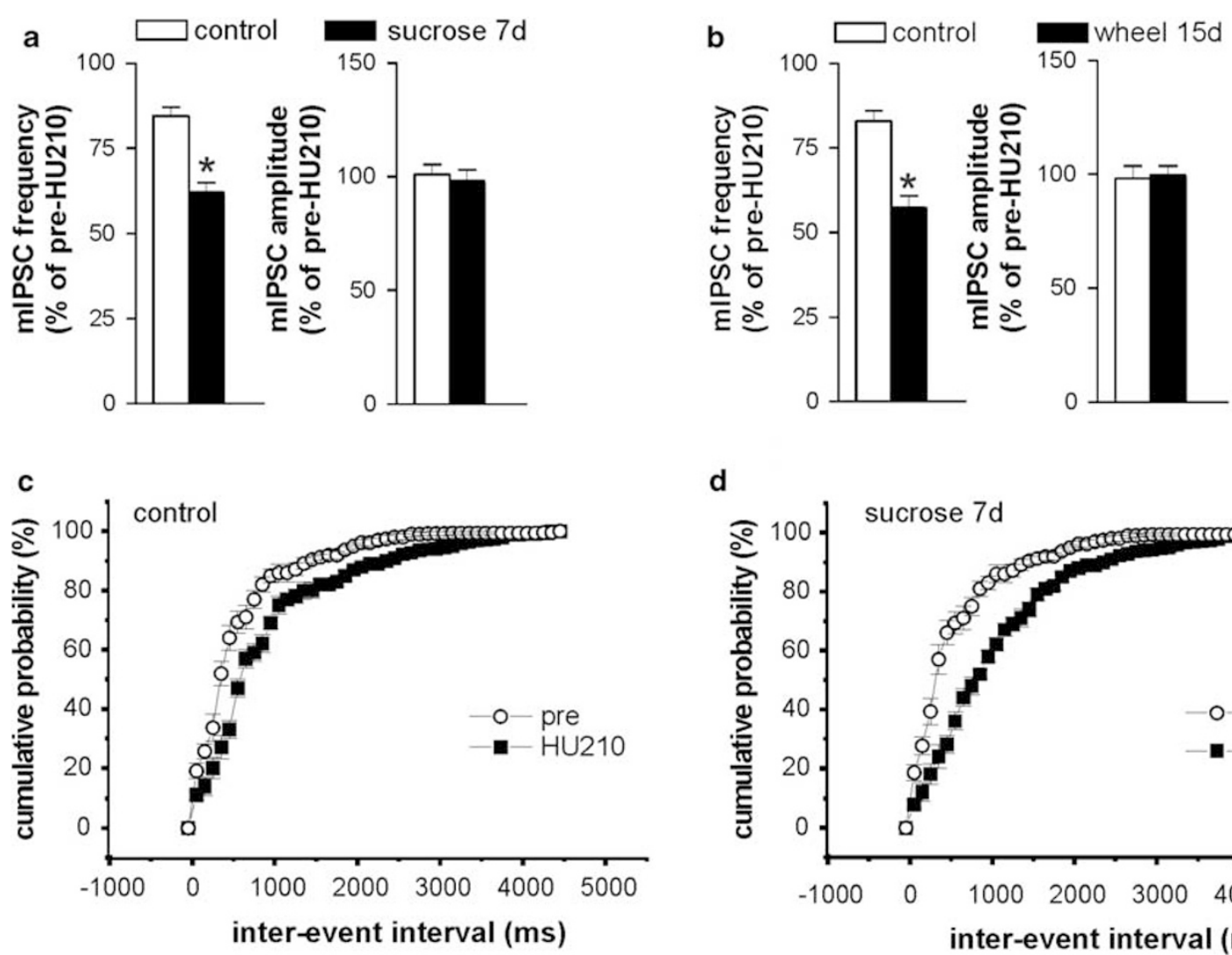

d
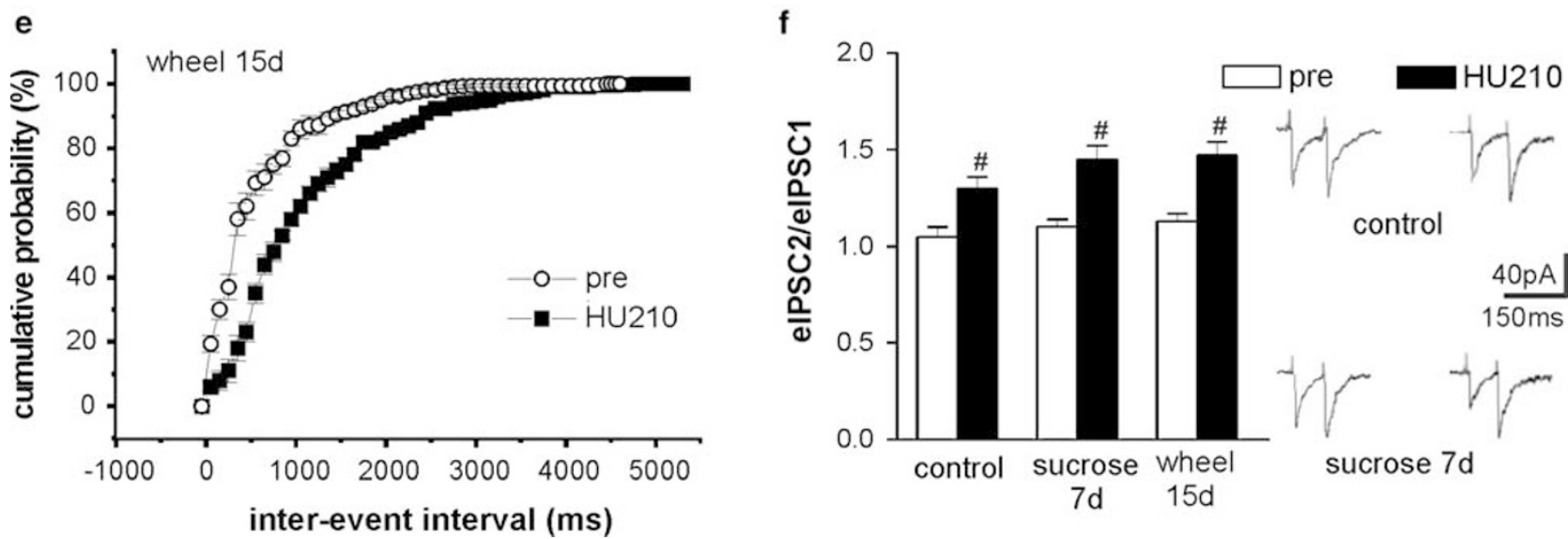

Figure 2 Running wheel and sucrose consumption potentiate the effects of HU2 IO through a presynaptic action. (a and b) The activation of CBI receptors with HU2IO reduced mIPSC frequency but not amplitude in control and in rewarded mice. In sucrose (7 days)-receiving mice (a) and in wheel ( 15 days)-exposed mice (b), the effect of HU2 IO was potentiated. (c-e) Cumulative distribution of mIPSC inter-event interval recorded before and during HU2 10 application from control mice (c), sucrose (7 days)-receiving mice (d), and wheel ( 15 days)-exposed mice (e). ( $f$ ) HU2 I 0 enhanced PPR of elPSCs in neurons recorded from control and rewarded mice. Samples of PPR recordings before and during the application of HU2 I 0 in control (upper traces) and sucrose ( 7 days)-receiving mice (lower traces) are shown on the right. ${ }^{*} p<0.05$ compared with control, ${ }^{*} p<0.05$ compared with pre-drug values.

a significant increase in PPR (eIPSC2/eIPSC1), as expected for a presynaptic action of the drug $(p<0.05$ for the three groups) (Figure 2f). Consistent with the data on sIPSCs and on mIPSCs, the effect of HU210 on eIPSC1 was potentiated in running wheel (15 days)- or sucrose (7 days)-exposed mice compared with HU210 effects in controls (eIPSC amplitude with respect to pre-drug values: $74 \pm 3 \%$ (control), $52 \pm 5 \%$ (running wheel), and $56 \pm 4 \%$ (sucrose); $p<0.05)$.
Spontaneous IPSCs, mIPSCs and eIPSCs were fully blocked by bicuculline in control mice, as well as in mice with access to running wheel (15 days) or to sucrose-containing drinking solution $(7$ days $) \quad(n=$ at least 8 for the three synaptic parameters and the three experimental groups), indicating that these synaptic events were entirely mediated in the three experimental groups by the stimulation of GABAA receptors (data not shown). 


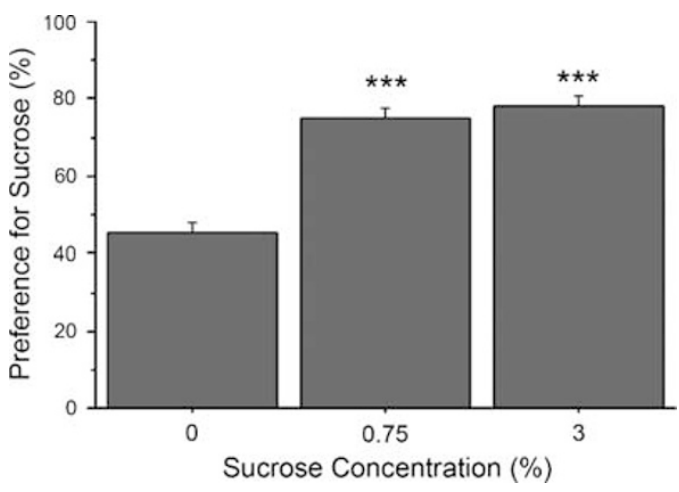

Figure 3 Hedonic effect of sucrose in C57BL/6) mice. Two-bottle freechoice sucrose preference test, carried out in control mice $(n=1 \mid$ per sucrose concentration), indicates that both 0.75 and $3 \%$ concentrations exert similar rewarding responses. Preference for sucrose, expressed in percentage, was used as dependent variable. $* * * * 0<0.0001$, compared with control water bottle (Fisher's post-hoc comparison). All values are expressed as mean \pm SEM.

\section{Rewarding Properties of Sucrose and of Exercise in Mice}

The rewarding properties of running wheel have already been established in previous studies. Rodents, for example, show CPP to an environment associated with wheel running (Iversen, 1993; Belke, 1997; Lett et al, 2000; de Visser et al, 2007), and show withdrawal signs when access to the running wheels is denied (Hoffmann et al, 1987).

The rewarding properties of sucrose drinking are less extensively investigated (Lenoir et al, 2007). Thus, in order to see whether at the dose here used sucrose elicits hedonic effects, we carried out a two-bottle preference test. The behavioral results showed that, at both concentrations tested $(0.75$ and $3.0 \%)$, sucrose induced in mice a robust rewarding response (Figure 3). Accordingly, one-way ANOVA indicated an overall impact of sucrose on drinking preference of mice $\left(\mathrm{F}_{2,20}=46.391, p<0.0001\right)$. Moreover, Fisher's post-hoc comparisons showed a similar pleasurable effect of both doses on mice (water vs $0.75 \%$ : $p<0.0001$; water vs 3.0\%: $p<0.0001$; and 0.75 vs 3\% sucrose: $p>0.1$ ).

Cages equipped with a running wheel could increase sensory stimulation, and this might in principle sensitize GABA synapses to HU210 effects by acting as an enriched environment, independently of increased motor activity. Thus, to dissect the role of voluntary exercise from that of sensory enrichment, we measured the effects of HU210 on sIPSCs in mice reared for 15 days in cages equipped with a wheel with blocked movement. In these mice, HU210 produced an inhibition of sIPSCs that was comparable with that seen in animals housed in standard cages $(19 \pm 2 \% v s$ $21 \pm 3 \% ; n=8$ for both groups, $p>0.05$ ) (data not shown).

\section{Dose-Response Relationship for HU210 Effects in Mice Exposed to Running Wheel or Sucrose}

A lower concentration of HU210 $(0.1 \mu \mathrm{M})$ was ineffective in control mice $(n=7, p>0.05)$, as well as in animals exposed to running wheel (15 days, $n=8, p>0.05$ ) or to sucrose (7 days, $n=8, p>0.05$ ), whereas at concentrations of $0.3,1$, and $3 \mu \mathrm{M}$ HU210 dose-dependently inhibited sIPSCs in the

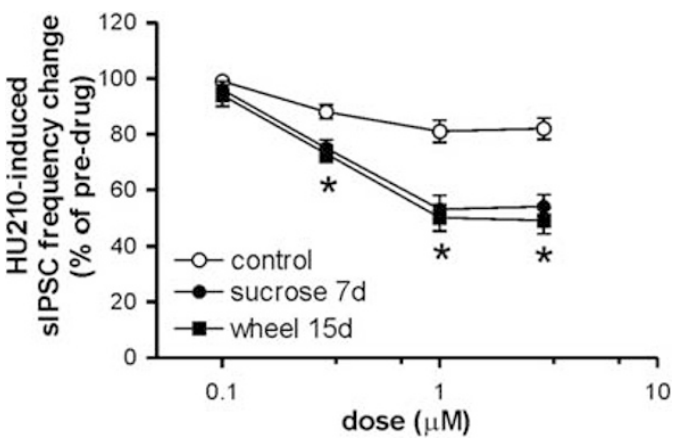

Figure 4 Cannabinoid receptor activity after running wheel or sucrose consumption. The histogram shows the dose-response relationship for $\mathrm{HU2} 10$ effects in rewarded and control mice. ${ }^{*} p<0.05$.

three groups. It can be noted that, the effects recorded from animals exposed to running wheel or to sucrose were remarkably more evident with the three concentrations of the agonist $(p<0.05)(n=$ at least 7 for each drug dose and experimental group), although $\mathrm{EC}_{50}$ values were similar (control: $0.30 \mu \mathrm{M}$; running wheel: $0.33 \mu \mathrm{M}$; and sucrose: $0.32 \mu \mathrm{M}$ ) (Figure 4).

\section{Effect of Time on Running Wheel- and Sucrose-Induced Sensitization of CB1 Receptors}

The running wheel or sucrose effects were slowly reversible after the discontinuation of both treatments, so that the sensitivity of sIPSCs to HU210 returned to control values after 3 days of sucrose discontinuation $(n=6, p>0.05$ compared with controls) or after 7 days of running wheel discontinuation $(n=7, p>0.05)$ (Figure 5).

\section{Effects of Baclofen on GABA Transmission after Running Wheel and Sucrose Consumption}

Many receptors participate in the presynaptic modulation of GABA transmission in the striatum, including the GABAB receptors (Calabresi et al, 1991). Thus, we investigated whether the abnormal control of GABA synapses observed in rewarded mice was specific only for $\mathrm{CB} 1$ receptors or also involved other presynaptic receptors. Application of the GABAB receptor agonist baclofen (10 min) dose-dependently reduced striatal sIPSC frequency in control mice $(n=8$ and $p<0.01$ for both 3 and $10 \mu \mathrm{M}$ baclofen). In neurons from mice exposed to sucrose (7 days) or to running wheel (15 days), the effects of baclofen were similar to those observed in control animals $(n=$ at least 8 for each experimental group and baclofen concentration, $p>0.05$ compared with baclofen in nonrewarded mice) (Figure 6). Statistical analysis carried out by taking the mean of the data from single animals confirmed the effects of baclofen on sIPSC frequency (at $10 \mu \mathrm{M}$, control mice $(n=6): 53 \pm 3 \%$; sucrose-exposed mice $(n=6)$ : $55 \pm 6 \%$; and running wheel-exposed mice $(n=7)$ : $57 \pm 5 \% ; p>0.05)$. 

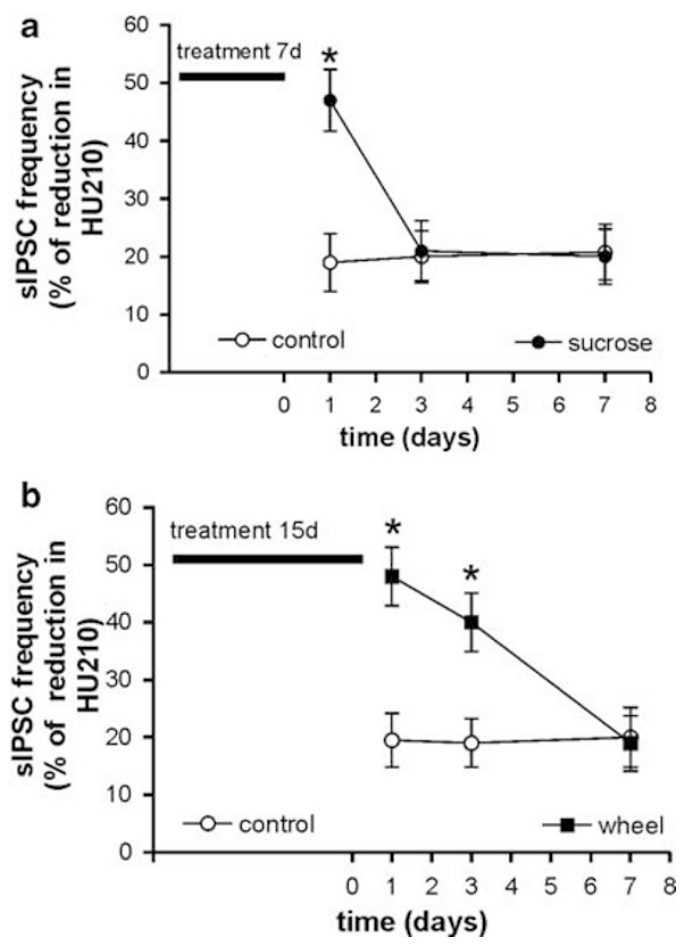

Figure 5 Effects of time on running wheel- and sucrose-induced sensitization of cannabinoid receptors. (a) The graph shows that the depressant effects of HU2IO on sIPSC frequency were still potentiated in mice exposed for 7 days to sucrose-containing solution and recorded I day after. In mice recorded 3 and 7 days after the last exposure to sucrose, HU2 10 produced normal effects. (b) The depressant effects of HU2 10 on sIPSC frequency were still potentiated in mice exposed to running wheel for 15 days and recorded I and 3 days after. In mice recorded 7 days after the last exposure to running wheel, HU2I0 produced normal effects. ${ }^{*} p<0.05$ compared with control.

\section{Effects of DHPG on Striatal mIPSCs Following Running Wheel or Sucrose}

The activation of metabotropic glutamate receptors 5 by DHPG mobilizes endocannabinoids in the striatum (Jung et al, 2005), and this effect results in the inhibition of GABA-mediated mIPSCs through the stimulation of cannabinoid CB1 receptors (Centonze et al, 2007b; Maccarrone et al, 2008). In contrast, sIPSCs are initially increased by DHPG, because this agonist causes action potential discharge of striatal GABAergic interneurons in a endocannabinoid-independent manner (Centonze et al, 2007b).

Thus, to see whether running wheel or sucrose altered the sensitivity of GABA synapses not only to the synthetic cannabinoid HU210 but also to endogenous cannabinoids, we measured the effects of DHPG on striatal mIPSCs recorded from control mice and from mice exposed to running wheel for 15 days or to sucrose for 7 days. The application of DHPG (10 min, $n=10)$ significantly inhibited mIPSC frequency in control mice $(p<0.05$ with respect to pre-drug value), and produced a greater effect after running wheel or sucrose consumption ( $n=$ at least 11 and $p<0.05$ compared with controls for the two experimental groups) (Figure $7 \mathrm{a}$ and c). Statistical analysis carried out by taking the mean of the data from single animals confirmed these results (control mice $(n=7): 82 \pm 2 \%$; sucrose-exposed mice $(n=7): 72 \pm 3 \%$; and running wheel-exposed mice $(n=7): 70 \pm 3 \%$; $p<0.05)$.

AM251 fully blocked the effects of DHPG in control mice and in mice exposed to running wheel and to sucrose $(n=4$ and $p>0.05$ for each group) (Figure $7 \mathrm{~b}$ and $\mathrm{d}$ ).

\section{Effects of HU210 on Striatal Glutamate Transmission}

In the striatum, stimulation of cannabinoid CB1 receptors presynaptically reduces glutamatergic transmission (Gerdeman and Lovinger, 2001; Huang et al, 2001; Centonze et al, 2005). Thus, to see whether the altered response to cannabinoid receptor stimulation found in mice exposed to running wheel or to sucrose was restricted to GABAmediated sIPSCs or also involved glutamate transmission, we tested the effects of HU210 on glutamate-mediated sEPSCs. Frequency and amplitude of sEPSCs were not significantly different in control condition and after exposure to running wheel (15 days) and to sucrose ( 7 days) ( $n=14$ and $p>0.05$ for both parameters and each experimental group). HU210 (10 min) reduced the frequency of sEPSCs in all the tested neurons $(n=12$ and $p<0.05$ with respect to pre-drug values for each group), and produced remarkably similar effects in control mice and in running wheel- or sucrose-exposed mice ( $p>0.05$ compared with controls) (Figure 8). Statistical analysis carried out by taking the mean of the data from single animals confirmed the results (control mice $(n=6)$ : $80 \pm 3 \%$; sucrose-exposed mice $(n=6): 78 \pm 3 \%$; and running wheel-exposed mice $(n=6): 76 \pm 4 \%$; $p>0.05)$.

\section{Effects of Running Wheel or Sucrose on the Emotional Consequences of Stress}

We have recently described that the anxious state induced by chronic psychoemotional stress is associated with loss of cannabinoid CB1-mediated control of striatal sIPSCs (Rossi et al, 2008). Thus, we first assessed whether running wheelor sucrose-induced sensitization of cannabinoid CB1 receptors was associated with behavioral changes. Neither running wheel ( 15 days) nor sucrose ( 7 days) produced per se overt anti-anxiety effects, as shown in the open-field protocol (data not shown). We next investigated whether the sensitization of cannabinoid responses after both environmental manipulations may protect from both the emotional and synaptic consequences of stress. Anxiety of mice was shown by their motor behavior in an aversive open-field environment. We studied locomotor activity of mice daily exposed to a stressing aggressor or given access for 15 days to running wheel or for 7 days to sucrose before stress induction, and compared their motor responses with that of control standard-housed animals. The analysis of total distance traveled by one-way ANOVA showed a significant effect of treatment $\left(\mathrm{F}_{3,41}=3.641, p=0.0204\right)$. Following post-hoc comparison (Student's $t$-test) showed that mice exposed to social stress were significantly less active than control littermates $(p=0.0061)$. In contrast, animals exposed to running wheel (15 days) or to sucrose solution ( 7 days) before daily aggressions showed a locomotor activity comparable with that of control mice (running wheel, $p=0.8915$; sucrose, $p=0.8164$ ) (Figure 9a). Further dissection of horizontal locomotion, measured in 

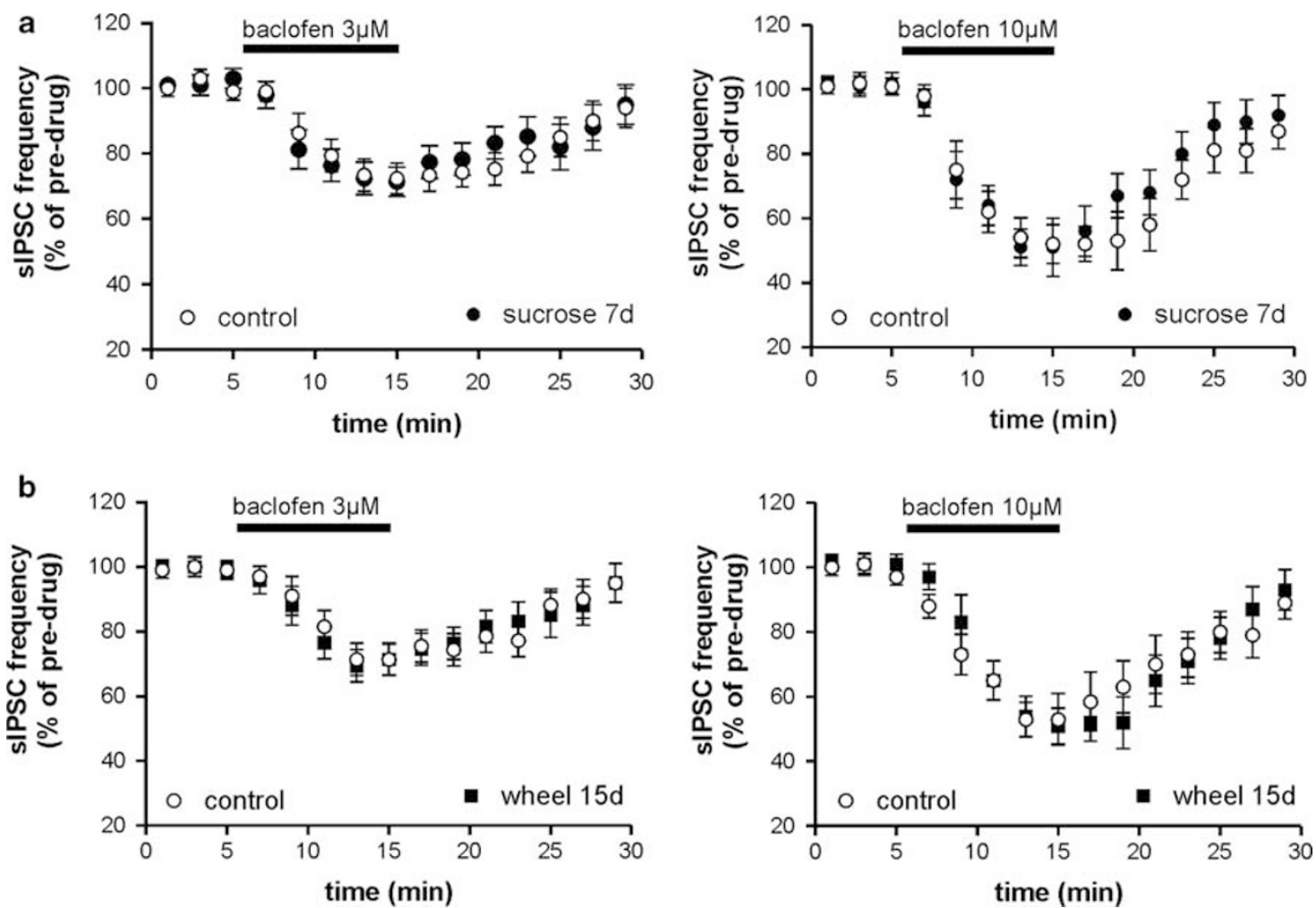

Figure 6 Running wheel and sucrose consumption potentiate the effects of HU2 I0 on striatal sIPSC through a specific pre-synaptic action. (a and b) The depressant effect of baclofen ( 3 and $10 \mu \mathrm{M}$ ) on sIPSC frequency was similar in control mice, in sucrose (7 days)-receiving mice (a) and in wheel (I5 days)exposed mice (b).

time intervals, confirmed a dramatic stress-induced hypoactive phenotype of mice exposed to aggressor (twoway ANOVA: treatment effect: $\mathrm{F}_{1,46}=7.602, p=0.0112$; treatment $\times$ time interaction: $\mathrm{F}_{2,46}=5.416, \quad p=0.0077$ ) (Figure 9b). In contrast, motor activity profile was normal in pre-rewarded animals (running wheel: treatment effect, $\mathrm{F}_{1,42}=0.012, p=0.9124$; treatment $\times$ time interaction: $\mathrm{F}_{2,42}=$ $0.539, p=0.5874$; sucrose: treatment effect, $\mathrm{F}_{1,42}=0.034$, $p=0.8563$; treatment $\times$ time interaction: $\mathrm{F}_{2,42}=1.312$, $p=0.2802$ ). In the open-field test, center/total distance ratio can be used as an index of anxiety-related responses, as anxiety reduces the time spent in the center of the arena. The analysis of center/total distance ratio showed a significant increase in anxiety in mice exposed to stress, as they spent a shorter time in the center of the arena compared with standard-housed mice (two-way ANOVA: treatment effect, $\mathrm{F}_{1,46}=13.249, \quad p=0.0014$; treatment $\times$ time interaction, $\mathrm{F}_{2,46}=2.086, \quad p=0.1358$ ) (Figure 9c). Conversely, cage enrichment with both running wheel and sucrose was able to completely reverse the anxiogenic effect of social defeat stress (running wheel: treatment effect, $\mathrm{F}_{1,42}=0.248, p=$ 0.6238 , treatment $\times$ time interaction, $\mathrm{F}_{2,42}=0.055, p=0.9464$; sucrose: treatment effect, $\mathrm{F}_{1,42}=1.960, p=0.1761$, treatment $\times$ time interaction, $\mathrm{F}_{2,42}=0.923, p=0.4053$ ).

Consistently with the behavioral data described above, both sucrose (7 days) and running wheel (15 days) also protected from the synaptic consequences of stress, as HU210 did not reduce sIPSC frequency in stressed animals ( $n=8, p>0.05$ compared with pre-HU210 values), but was able to inhibit these GABA-mediated synaptic events after 3 days of stress in mice previously exposed to the running wheel ( $n=9, p<0.01$ compared with pre-HU210 values) or to the sucrose-containing drinking solution $(n=11, p<0.01$ compared with pre-HU210 values) (Figure 9d).

\section{Role of Cannabinoid CB1 Receptors in the Effects of Running Wheel or Sucrose against Stress}

To establish a causal link between the activity of cannabinoid $\mathrm{CB} 1$ receptors and the protective effects of both exercise and sucrose against the behavioral consequences of stress, mice pre-exposed to sucrose for 7 days $(n=8)$ or to running wheel for 15 days $(n=8)$ received three daily intraperitoneal injections of saline or of AM251 during the stress protocol. Rewarded mice treated with the cannabinoid CB1 receptor antagonist AM251 showed an anxious behavior after exposure to the aggression, as they showed a hypoactive phenotype similar to that seen in nonrewarded mice exposed to the aggressions $(\mathrm{F}=0.04$, $p=0.09$ ) (Figure 10a), and spent less time in the center of the arena, as non-rewarded stressed mice (running wheel + AM251: treatment effect, $\mathrm{F}=0.19, p=0.61$, treatment $\times$ time interaction, $\mathrm{F}=0.09, p=0.82$; sucrose + AM251: treatment effect, $\mathrm{F}=0.22, p=0.53$, treatment $\times$ time interaction, $\mathrm{F}=0.08, p=0.87$ ) (Figure 10b). These data suggest a protective role of preserved $\mathrm{CB} 1$ receptor activity against stress after environmental manipulations associated with reward. 


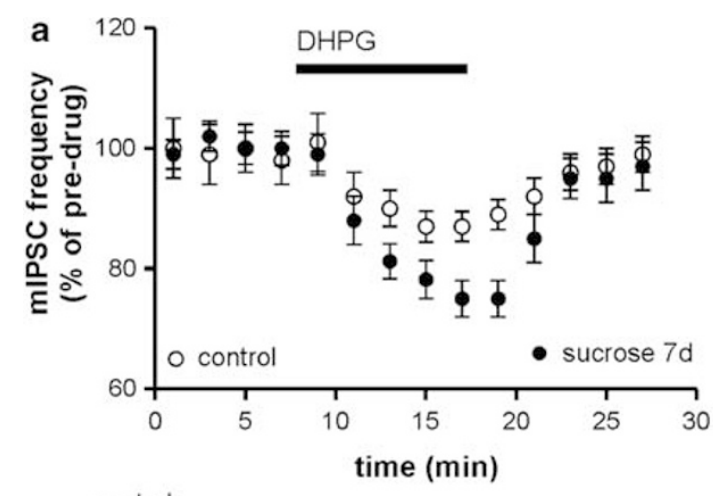

control
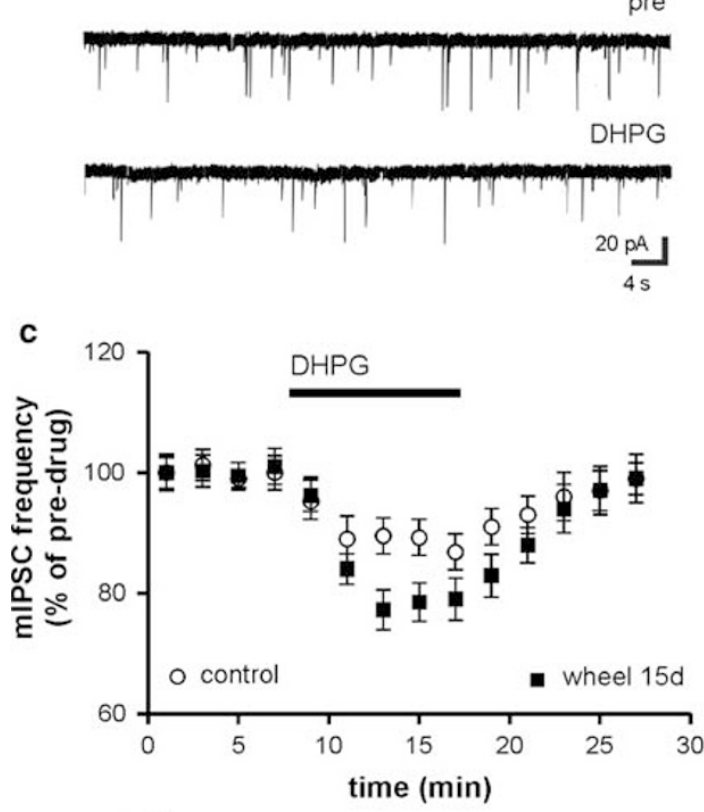

control

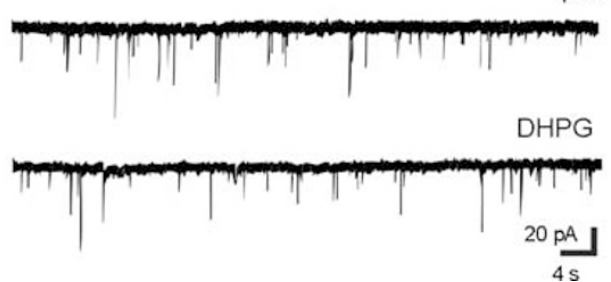

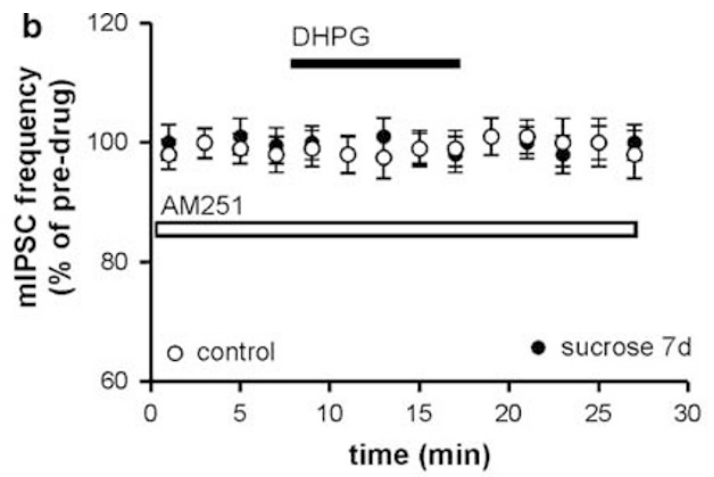

sucrose $7 d$
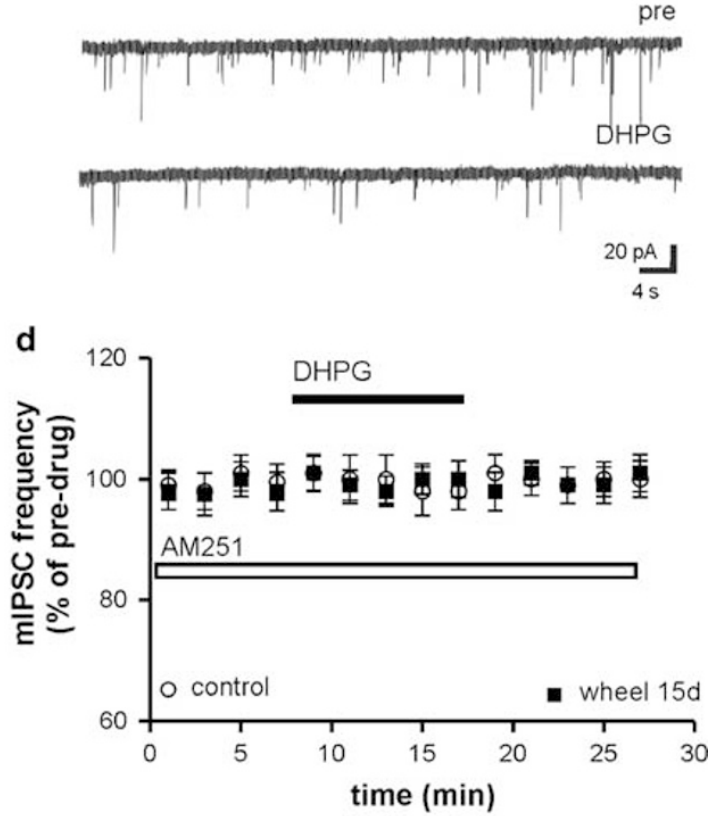

wheel $15 d$

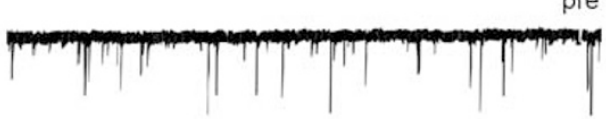

DHPG

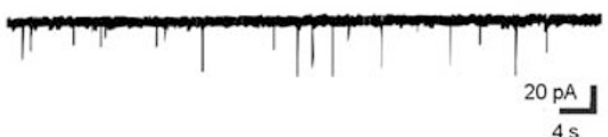

Figure 7 Effects of DHPG on striatal mIPSCs. (a) The reduction of mIPSC frequency after the application of the group I mGlu receptor agonist DHPG was potentiated in sucrose (7 days)-treated mice. (b) Preincubation with the CBI receptor antagonist AM25I prevented the depressant action of DHPG in control and sucrose (7 days)-receiving mice. Traces in the bottom are voltage-clamp recordings before and during the application of DHPG in control and sucrose (7 days)-treated mice. (c) The graph shows that the reduction of mIPSC frequency after the application of DHPG was increased by running wheel (I 5 days). (d) Preincubation with AM25 I prevented the depressant action of DHPG in control and in running wheel (I5 days)-exposed mice. The traces on the bottom are examples of voltage-clamp recordings before and during the application of DHPG in control and in running wheel (I5 days)-exposed mice.

\section{DISCUSSION}

This study shows that wheel running and sucrose consumption cause significant adaptations of cannabinoid CB1 receptor-mediated control of GABA transmission in the striatum and provide an emotional reserve against the effects of stress. A similar synaptic effect was achieved in animals chronically exposed to cocaine (Centonze et al, 2007a), suggesting that changes in the sensitivity of striatal cannabinoid receptors represent a common synaptic correlate of the activation of the central reward pathway.

The synaptic responses to the selective cannabinoid CB1 receptor agonist HU210 were normal after a single day of exposure to running wheel or to sucrose, but remarkably potentiated after 7 days of treatments, indicating that cannabinoid receptors progressively adapt during these environmental manipulations. Furthermore, the synaptic adaptations caused by both exercise and sucrose exposure 


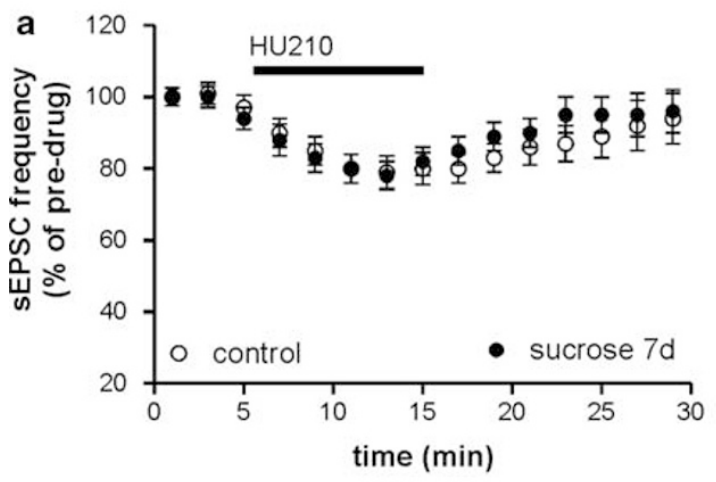

control
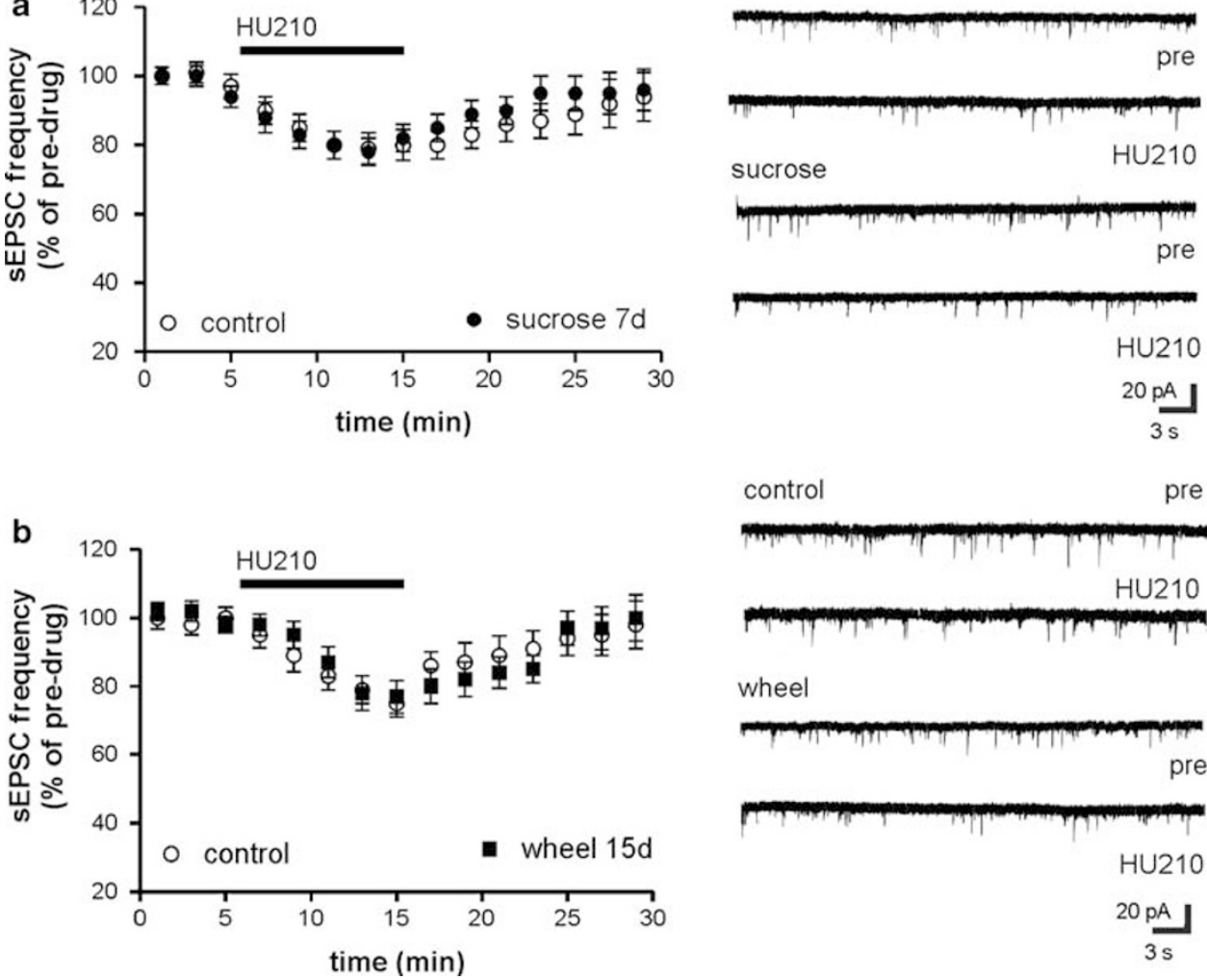

Figure 8 Effects of HU2IO on striatal glutamatergic transmission. (a) The depressant effects of HU2 IO on sEPSC frequency were similar in control and in mice exposed to sucrose (7 days)-containing solution. The electrophysiological traces on the right are examples of sEPSCs before and during the application of HU2 10 in control and sucrose (7 days)-exposed mice. (b) The depressant effects of HU2 10 on sEPSC frequency were comparable in control and in running wheel ( 15 days)-exposed animals. The electrophysiological traces on the right are examples of voltage-clamp recordings before and during the application of HU2 10 in control and running wheel ( 15 days)-exposed mice.

were slowly reversible after the discontinuation of the treatments, indicating that they were not irreversible.

Running wheel or sucrose selectively altered the sensitivity of cannabinoid receptors controlling GABA transmission in the striatum, whereas the sensitivity of glutamate synapses to $\mathrm{CB} 1$ receptor stimulation was unaltered, indicating the existence of differential regulation mechanisms of distinct cannabinoid receptors. The effects of cannabinoid CB1 receptor stimulation on sensitized striatal GABA synapses were mediated by a presynaptic mechanism in mice exposed to running wheel or to sucrose, as HU210 selectively reduced sIPSC and mIPSC frequency without altering their amplitudes, and depressed eIPSCs by enhancing PPR. These findings are compatible with the preferential location of $\mathrm{CB} 1$ receptors on GABAergic nerve terminals described in the striatum (Narushima et al, 2007; Uchigashima et al, 2007). Our data also show that the tested environmental manipulations do not result in a widespread dysregulation of the presynaptic control of striatal GABA synapses, as they did not alter the sensitivity of sIPSCs to the stimulation of other G-alpha-i/o-coupled receptors, such as $\mathrm{GABAB}$ receptors.

We have also shown that running wheel or sucrose altered the synaptic effects not only of the exogenous cannabinoid HU210 but also of endocannabinoids mobilized in the striatum in response to mGlu 5 receptor stimulation. This finding suggests that these alterations of cannabinoid transmission may have relevant synaptic consequences during the physiological activity of the striatum, which is mainly driven by glutamate inputs originating from the cortex and the thalamus (Wilson and Kawaguchi, 1996; Stern et al, 1998). It should be noted that the normal sensitivity of glutamate synapses to the stimulation of cannabinoid CB1 receptors supports the concept that glutamatergic drive to the striatum is intact after running wheel or sucrose drinking, and that the resulting mGlu 5 receptor activation may selectively impact GABA transmission because of the sensitized CB1 receptors controlling transmitter release.

The source of GABA inputs to striatal neurons is dual. Accordingly, striatal GABAergic principal neurons, besides inhibiting basal ganglia output nuclei, form functional synapses through their recurrent axon collaterals, establishing a feedback control over striatal neuron activity (Tunstall et al, 2002; Guzman et al, 2003; Koos et al, 2004; Gustafson et $a l, 2006)$. Inputs from GABAergic interneurons are another important source of synaptic inhibition of projection neurons, giving rise to a feed-forward inhibitory pathway that is independent of striatal output (Plenz 2003; Tepper et al, 2004; Gustafson et al, 2006). Both the feedback and the feed-forward intrastriatal GABAergic pathways are likely modulated by cannabinoid $\mathrm{CB} 1$ receptors and undergo adaptations following wheel running or sucrose consumption. In line with this conclusion, CB1 receptors are expressed at very high concentrations on both axon collaterals of striatal projection neurons and on GABA 

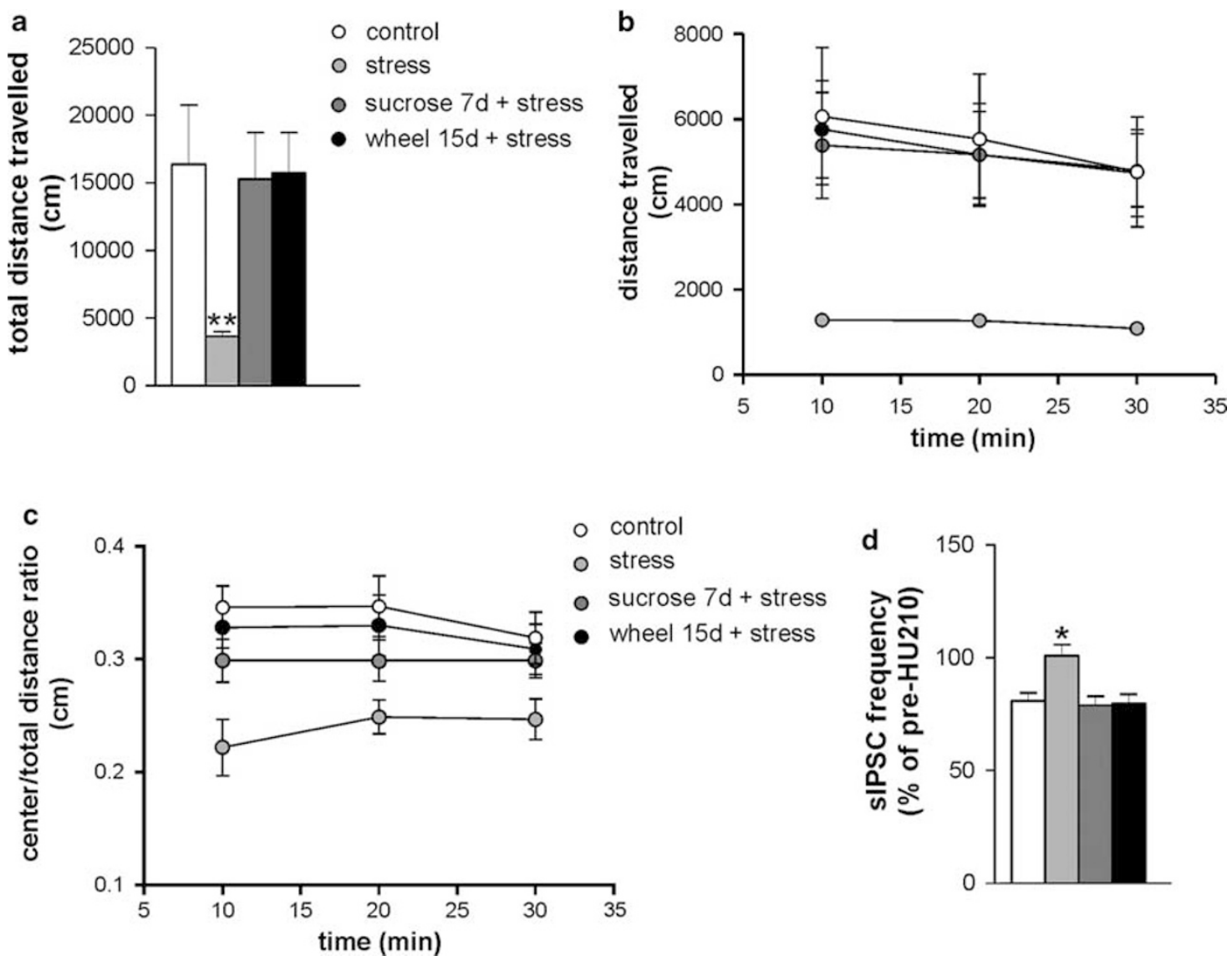

Figure 9 Running wheel and sucrose consumption protect mice from the behavioral effect of social defeat stress. Mice were allowed to explore an openfield box for $30 \mathrm{~min}$. (a) Total distance traveled by mice subjected to social stress was significantly reduced compared with non-stressed animals. On the contrary, mice previously exposed to 15 days of running wheel or to 7 days of sucrose consumption showed a locomotor activity comparable with controls. (b) Similar results were obtained by recording the profile of locomotion over successive 10-min intervals. (c) The distance covered in the center compared with the total distance was used as a parameter of anxiety-related behavior. In accordance to motor activity, this index of emotionality showed that running wheel and sucrose rewards are able to prevent stress-induced anxiety. Indeed, mice exposed to natural rewards before stress showed distance ratios comparable with those of their control non-stressed littermates. (d) The graph shows the protective action of natural rewards from the synaptic consequences of stress: sucrose ( 7 days) treatment and running wheel ( 15 days) exposure were able to rescue the effect of HU2 I 0 on sIPSC frequency. $* p<0.05$ compared with control mice. $* * * 0.01$ compared with control mice.

interneurons (Herkenham et al, 1991; Hohmann and Herkenham, 2000).

Our previous report indicated that hypersensitivity of striatal GABA synapses to HU210 tightly correlated with the rewarding properties of cocaine, as this synaptic alteration appeared only when a CPP was induced. A single cocaine exposure that failed to induced CPP, conversely, also failed to sensitize striatal cannabinoid receptors (Centonze et al, 2007a). It can be noted that, the CPP procedure selectively examines the positive reinforcing properties of addictive compounds (Acquas and Di Chiara, 1994; Tzschentke, 1998; Le Foll and Goldberg, 2005), and previous behavioral studies indicated that the (endo)cannabinoid system, rather than contributing to the hedonic or psychomotor effects of cocaine consumption, is involved in the generation and maintenance of rewardbased addictive behavior (De Vries and Schoffelmeer, 2005; Le Foll and Goldberg, 2005; Parolaro et al, 2005). Here, we have observed that voluntary wheel running and sucrose consumption share with chronic cocaine the common neurobiological background of increasing the sensitivity of cannabinoid receptors modulating GABA transmission in the striatum (Centonze et al, 2007a). It is conceivable, therefore, that this alteration might represent a synaptic correlate of reward-based behavior. Evidence of the rewarding and potentially addictive properties of running wheel is currently accumulating. Rodents, in fact, are highly motivated to gain access to running wheels and display CPP to an environment associated with wheel running (Iversen, 1993; Belke, 1997; Lett et al, 2000; de Visser et al, 2007). Furthermore, animals that run long distances daily show withdrawal signs when access to the running wheels is denied (Hoffmann et al, 1987), and display increased vulnerability for cocaine self-administration and reinstatement after abstinence (Larson and Carroll, 2005). On the other hand, intense rewarding properties of sucrose have also been reported (Lenoir et al, 2007), and similar activation of the central reward pathway has been found after sweet tasting (Mark et al, 1991; Hajnal et al, 2004) and drugs of abuse (Di Chiara and Imperato, 1988; Pontieri et al, 1996). Furthermore, some behavioral and neurochemical signs of opiate withdrawal can be precipitated by naloxone in rats with sugar overconsumption (Colantuoni et al, 2004). 

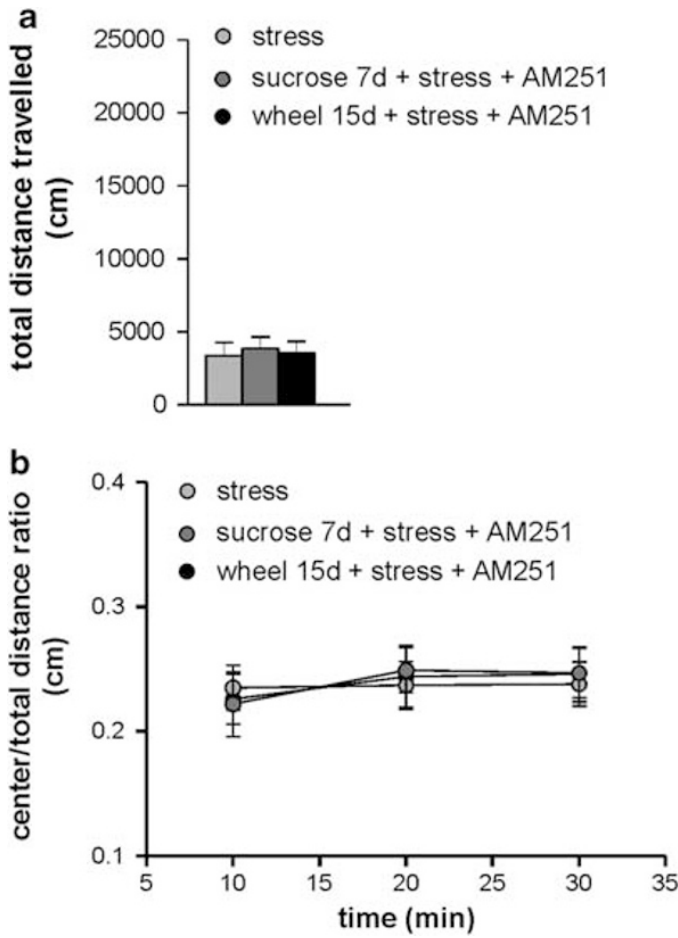

Figure 10 Behavioral effects of AM25I in mice exposed to running wheel or to sucrose before the stress procedure. ( $a$ and $b$ ) Blockade of $\mathrm{CB}$ I receptors prevented the protective action of both running wheel and sucrose consumption on the motor effect of stress.

Wheel running, however, also has a strong motor activating effect in mice, and the relationship between this experimental procedure and the mechanisms of reward is unclear, especially when animals are housed in groups, as in the case of this study. Similarly, at least in part, the effects of sucrose on cannabinoid CB1 receptors might also be unrelated to its rewarding properties, and reflect, for example, increased caloric assumption. However, we found striking similarities between the neurophysiological and behavioral effects of running wheel and of sucrose, which has reinforcing properties but not motor activating effects. These findings suggest, therefore, that the alteration of cannabinoid CB1 receptor function here described likely reflect the emotional effects of the two experimental paradigms, as also indicated by the evidence that cannabinoid CB1 receptor blockade abolishes the protective action of both running wheel and of sucrose on stress-induced behavior.

The DA system might have an important role in the sensitization of cannabinoid CB1 receptors after exercise or sucrose consumption, as both manipulations activate the DA system in the striatum (Mark et al, 1991; Hajnal et al, 2004; El Rawas et al, 2009), and stimulation of D2-like receptors increase endocannabinoid levels (Giuffrida et al, 1999; Beltramo et al, 2000; Centonze et al, 2004), and upregulates the expression of $\mathrm{CB} 1$ receptors in the striatum (Centonze et al, 2004). Furthermore, endocannabinoids act as downstream effectors of D2-like receptor signaling in the inhibition of GABA transmission (Centonze et al, 2004), and in the generation of corticostriatal long-term depression, a form of synaptic plasticity believed to underlie specific aspects of reward-based learning and psychostimulant addiction (Gerdeman et al, 2002, 2003).

The commonalities among running wheel, sucrose consumption, and cocaine exposure might suggest that natural and drug-induced rewards trigger a common synaptic adaptation involving cannabinoid CB1-mediated transmission in the striatum. The importance of this adaptation in the behavioral consequences of the activation of the central reward pathway is evident when considering that exercise activates the endocannabinoid system also in humans (Sparling et al, 2003), and that both the motivation for sweet food (Simiand et al, 1998; Cota et al, 2003; Ward and Dykstra, 2005; Mahler et al, 2007) and the rewarding properties of cocaine (Chaperon et al, 1998) are significantly attenuated after the blockade of cannabinoid CB1 receptors.

Finally, our present results also show that voluntary exercise and sucrose consumption exert protective effects against the motor behavior induced by stress, and that the sensitization of cannabinoid CB1-mediated synaptic responses in the striatum are likely involved in these effects. Consistently, previous study proposed an association between stress-induced emotional alterations and the downregulation of striatal cannabinoid CB1 receptormediated transmission (Rossi et al, 2008), and pharmacological blockade of $\mathrm{CB} 1$ receptors abolished the protective effects of both running wheel and sucrose drinking against stress (this study).

\section{ACKNOWLEDGEMENTS}

This investigation was supported by grants from the Italian Ministero dell'Università e della Ricerca and from the Italian Ministero della Salute to DC. AU represents Mariano Scippacercola Foundation.

\section{DISCLOSURE}

The authors declare no conflict of interest.

\section{REFERENCES}

Acquas E, Di Chiara G (1994). D1 receptor blockade stereospecifically impairs the acquisition of drug-conditioned place preference and place aversion. Behav Pharmacol 5: 555-569.

Avgustinovich DF, Kovalenko IL, Koryakina LA (2005). A model of anxious depression: persistence of behavioral pathology. Neurosci Behav Physiol 35: 917-924.

Belke TW (1997). Running and responding reinforced by the opportunity to run: effect of reinforcer duration. J Exp Anal Behav 67: 337-351.

Beltramo M, de Fonseca FR, Navarro M, Calignano A, Gorriti MA, Grammatikopoulos G et al. (2000). Reversal of dopamine D(2) receptor responses by an anandamide transport inhibitor. J Neurosci 20: 3401-3407.

Berton O, McClung CA, Dileone RJ, Krishnan V, Renthal W, Russo SJ et al. (2006). Essential role of BDNF in the mesolimbic dopamine pathway in social defeat stress. Science 311: 864-868.

Calabresi P, Mercuri NB, De Murtas M, Bernardi G (1991). Involvement of GABA systems in feedback regulation of glutamate-and GABA-mediated synaptic potentials in rat neostriatum. J Physiol 440: 581-599. 
Centonze D, Battista N, Rossi S, Mercuri NB, Finazzi-Agro A, Bernardi $G$ et al. (2004). A critical interaction between dopamine D2 receptors and endocannabinoids mediates the effects of cocaine on striatal GABAergic transmission. Neuropsychopharmacology 29: 1488-1497.

Centonze D, Rossi S, De Chiara V, Prosperetti C, Battista N, Bernardi $G$ et al. (2007a). Chronic cocaine sensitizes striatal GABAergic synapses to the stimulation of cannabinoid CB1 receptors. Eur J Neurosci 25: 1631-1640.

Centonze D, Rossi S, Prosperetti C, Gasperi V, De Chiara V, Bari M et al. (2007b). Endocannabinoids limit metabotropic glutamate 5 receptor-mediated synaptic inhibition of striatal principal neurons. Mol Cell Neurosci 35: 302-310.

Centonze D, Rossi S, Prosperetti C, Tscherter A, Bernardi G, Maccarrone $\mathrm{M}$ et al. (2005). Abnormal sensitivity to cannabinoid receptor stimulation might contribute to altered gammaaminobutyric acid transmission in the striatum of R6/2 Huntington's disease mice. Biol Psychiatry 57: 1583-1589.

Chaperon F, Soubrie P, Puech AJ, Thiebot MH (1998). Involvement of central cannabinoid (CB1) receptors in the establishment of place conditioning in rats. Psychopharmacology 135: 324-332.

Colantuoni C, Rada P, McCarthy J, Patten C, Avena NM et al (2004). Evidence that intermittent, excessive sugar intake causes endogenous opioid dependence. Obes Res 10: 478-488.

Cossu G, Ledent C, Fattore L, Imperato A, Bohme GA, Parmentier $\mathrm{M}$ et al. (2001). Cannabinoid CB1 receptor knockout mice fail to self-administer morphine but not other drugs of abuse. Behav Brain Res 118: 61-65.

Cota D, Marsicano G, Lutz B, Vicennati V, Stalla GK, Pasquali R et al. (2003). Endogenous cannabinoid system as a modulator of food intake. Int J Obes Relat Metab Disord 27: 289-301.

d'Anci KE, Kanarek RB, Marks-Kaufman R (1996). Duration of sucrose availability differentially alters morphine-induced analgesia in rats. Pharmacol Biochem Behav 54: 693-697.

de Visser L, van den Bos R, Stoker AK, Kas MJ, Spruijt BM (2007). Effects of genetic background and environmental novelty on wheel running as a rewarding behaviour in mice. Behav Brain Res 177: 290-297.

De Vries TJ, Schoffelmeer AN (2005). Cannabinoid CB1 receptors control conditioned drug seeking. Trends Pharmacol Sci 26: 420-426.

Di Chiara G, Imperato A (1988). Drugs abused by humans preferentially increase synaptic dopamine concentrations in the mesolimbic system of freely moving rats. Proc Natl Acad Sci USA 85: 5274-5278.

El Rawas R, Thiriet N, Lardeux V, Jaber M, Solinas M (2009). Environmental enrichment decreases the rewarding but not the activating effects of heroin. Psychopharmacology 203: 561-570.

Errico F, Santini E, Migliarini S, Borgkvist A, Centonze D, Nasti V et al. (2008). The GTP binding protein Rhes modulates dopamine signalling in striatal medium spiny neurons. Mol Cell Neurosci 37: 335-345.

Fattore L, Spano MS, Deiana S, Melis V, Cossu G, Fadda P et al. (2007). An endocannabinoid mechanism in relapse to drug seeking: a review of animal studies and clinical perspectives. Brain Res Rev 53: 1-16.

Gerdeman G, Lovinger DM (2001). CB1 cannabinoid receptor inhibits synaptic release of glutamate in rat dorsolateral striatum. J Neurophysiol 85: 468-471.

Gerdeman GL, Ronesi J, Lovinger DM (2002). Postsynaptic endocannabinoid release is critical to long-term depression in the striatum. Nat Neurosci 5: 446-451.

Gerdeman GL, Partridge JG, Lupica CR, Lovinger DM (2003). It could be habit forming: drugs of abuse and striatal synaptic plasticity. Trends Neurosci 26: 184-192.

Giuffrida A, Parsons LH, Kerr TM, Rodriguez de Fonseca F, Navarro M, Piomelli D (1999). Dopamine activation of endogenous cannabinoid signaling in dorsal striatum. Nat Neurosci 2: 358-363.

Gustafson N, Gireesh-Dharmaraj E, Czubayko U, Blackwell KT, Plenz D (2006). A comparative voltage and current-clamp analysis of feedback and feedforward synaptic transmission in the striatal microcircuit in vitro. $J$ Neurophysiol 95: 737-752.

Guzman JN, Hernandez A, Galarraga E, Tapia D, Laville A, Vergara $\mathrm{R}$ et al. (2003). Dopaminergic modulation of axon collaterals interconnecting spiny neurons of the rat striatum. J Neurosci 23: 8931-8940.

Hajnal A, Smith GP, Norgren R (2004). Oral sucrose stimulation increases accumbens dopamine in the rat. Am J Physiol Regul Integr Comp Physiol 286: R31-R37.

Herkenham M, Lynn AB, de Costa BR, Richfield EK (1991). Neuronal localization of cannabinoid receptors in the basal ganglia of the rat. Brain Res 547: 267-274.

Higuera-Matas A, Luisa Soto-Montenegro M, Del Olmo N, Miguéns M, Torres I, José Vaquero J et al. (2008). Augmented acquisition of cocaine self-administration and altered brain glucose metabolism in adult female but not male rats exposed to a cannabinoid agonist during adolescence. Neuropsychopharmacology 33: 806-813.

Hoffmann P, Thorén P, Ely D (1987). Effect of voluntary exercise on open-field behavior and on aggression in the spontaneously hypertensive rat (SHR). Behav Neural Biol 47: 346-355.

Hohmann AG, Herkenham M (2000). Localization of cannabinoid $\mathrm{CB}(1)$ receptor mRNA in neuronal subpopulations of rat striatum: a double-label in situ hybridization study. Synapse 37: 71-80.

Huang CC, Lo SW, Hsu KS (2001). Presynaptic mechanisms underlying cannabinoid inhibition of excitatory synaptic transmission in rat striatal neurons. $J$ Physiol 532: 731-748.

Iversen IH (1993). Techniques for establishing schedules with wheel running as reinforcement in rats. J Exp Anal Behav 60: 219-238.

Jung KM, Mangieri R, Stapleton C, Kim J, Fegley D, Wallace M et al. (2005). Stimulation of endocannabinoid formation in brain slice cultures through activation of group I metabotropic glutamate receptors. Mol Pharmacol 68: 1196-1202.

Kanarek RB, Mathes WF, Heisler LK, Lima RP, Monfared LS (1997). Prior exposure to palatable solutions enhances the effects of naltrexone on food intake in rats. Pharmacol Biochem Behav 57: $377-381$.

Kelley AE (2004). Memory and addiction: shared neural circuitry and molecular mechanisms. Neuron 44: 161-179.

Koos T, Tepper JM, Wilson CJ (2004). Comparison of IPSCs evoked by spiny and fast-spiking neurons in the neostriatum. J Neurosci 24: 7916-7922.

Larson EB, Carroll ME (2005). Wheel running as a predictor of cocaine self-administration and reinstatement in female rats. Pharmacol Biochem Behav 82: 590-600.

Ledent C, Valverde O, Cossu G, Petitet F, Aubert JF, Beslot F et al. (1999). Unresponsiveness to cannabinoids and reduced addictive effects of opiates in CB1 receptor knockout mice. Science 283: 401-404.

Le Foll B, Goldberg SR (2005). Cannabinoid CB1 receptor antagonists as promising new medications for drug dependence. J Pharmacol Exp Ther 312: 875-883.

Lenoir M, Serre F, Cantin L, Ahmed SH (2007). Intense sweetness surpasses cocaine reward. PLOS ONE 2: e698.

Lett BT, Grant VL, Byrne MJ, Koh MT (2000). Pairings of a distinctive chamber with the aftereffect of wheel running produce conditioned place preference. Appetite 34: 87-94.

Lett BT, Grant VL, Koh MT (2001). Naloxone attenuates the conditioned place preference induced by wheel running in rats. Physiol Behav 72: 355-358. 
Levine AS, Kotz CM, Gosnell BA (2003). Sugars: hedonic aspects, neuroregulation, and energy balance. Am J Clin Nutr 78: 834 S-842S.

Lieblich I, Cohen E, Ganchrow JR, Blass EM, Bergmann F (1983). Morphine tolerance in genetically selected rats induced by chronically elevated saccharin intake. Science 221: 871-873.

Maccarrone M, Rossi S, Bari M, De Chiara V, Fezza F, Musella A et al. (2008). Anandamide inhibits metabolism and physiological actions of 2-arachidonoylglycerol in the striatum. Nat Neurosci 11: 152-159.

Mahler SV, Smith KS, Berridge KC (2007). Endocannabinoid hedonic hotspot for sensory pleasure: anandamide in nucleus accumbens shell enhances 'liking' of a sweet reward. Neuropsychopharmacology 32: 2267-2278.

Mark GP, Blander DS, Hoebel BG (1991). A conditioned stimulus decreases extracellular dopamine in the nucleus accumbens after the development of a learned taste aversion. Brain Res 551: 308-310.

Martin M, Ledent C, Parmentier M, Maldonado R, Valverde O (2000). Cocaine, but not morphine, induces conditioned place preference and sensitization to locomotor responses in CB1 knockout mice. Eur J Neurosci 12: 4038-4046.

Narushima M, Uchigashima M, Fukaya M, Matsui M, Manabe T, Hashimoto $\mathrm{K}$ et al. (2007). Tonic enhancement of endocannabinoid-mediated retrograde suppression of inhibition by cholinergic interneuron activity in the striatum. J Neurosci 27: 496-506.

Parolaro D, Vigano D, Rubino T (2005). Endocannabinoids and drug dependence. Curr Drug Targets CNS Neurol Disord 4: 643-655.

Plenz D (2003). When inhibition goes incognito: feedback interaction between spiny projection neurons in striatal function. Trends Neurosci 26: 436-443.

Pontieri FE, Tanda G, Orzi F, Di Chiara G (1996). Effects of nicotine on the nucleus accumbens and similarity to those of addictive drugs. Nature 382: 255-387.

Rossi S, De Chiara V, Musella A, Kusayanagi H, Mataluni G, Bernardi G et al. (2008). Chronic psychoemotional stress impairs cannabinoid receptor-mediated control of GABA transmission in the striatum. J Neurosci 28: 7284-7292.

Rudski JM, Billington CJ, Levine AS (1997). A sucrose-based maintenance diet increases sensitivity to appetite suppressant effects of naloxone. Pharmacol Biochem Behav 58: 679-682.
Simiand J, Keane M, Keane PE, Soubrie P (1998). SR 141716, a CB1 cannabinoid receptor antagonist, selectively reduces sweet food intake in marmoset. Behav Pharmacol 9: 179-181.

Sonnier L, Le Pen G, Hartmann A, Bizot JC, Trovero F, Krebs MO et al. (2007). Progressive loss of dopaminergic neurons in the ventral midbrain of adult mice heterozygote for Engrailed1. J Neurosci 27: 1063-1071.

Sparling PB, Giuffrida A, Piomelli D, Rosskopf L, Dietrich A (2003). Exercise activates the endocannabinoid system. Neuroreport 14: 2209-2211.

Stern EA, Jaeger D, Wilson CJ (1998). Membrane potential synchrony of simultaneously recorded striatal spiny neurons in vivo. Nature 394: 475-478.

Tepper JM, Koos T, Wilson CJ (2004). GABAergic microcircuits in the neostriatum. Trends Neurosci 27: 662-669.

Tunstall MJ, Oorschot DE, Kean A, Wickens JR (2002). Inhibitory interactions between spiny projection neurons in the rat striatum. J Neurophysiol 88: 1263-1269.

Tzschentke TM (1998). Measuring reward with the conditioned place preference paradigm: a comprehensive review of drug effects, recent progress and new issues. Prog Neurobiol 56: 613-672.

Uchigashima M, Narushima M, Fukaya M, Katona I, Kano M, Watanabe M (2007). Subcellular arrangement of molecules for 2-arachidonoyl-glycerol-mediated retrograde signaling and its physiological contribution to synaptic modulation in the striatum. J Neurosci 27: 3663-3676.

Volkow ND, Wise RA (2005). How can drug addiction help us understand obesity? Nat Neurosci 8: 555-560.

Ward SJ, Dykstra LA (2005). The role of CB1 receptors in sweet versus fat reinforcement: effect of $\mathrm{CB} 1$ receptor deletion, $\mathrm{CB} 1$ receptor antagonism (SR141716A) and CB1 receptor agonism (CP-55940). Behav Pharmacol 16: 381-388.

Werme M, Thoren P, Olson L, Brene S (2000). Running and cocaine both upregulate dynorphin mRNA in medial caudate putamen. Eur J Neurosci 12: 2967-2974.

Werme M, Messer C, Olson L, Gilden L, Thoren P, Nestler EJ et al. (2002). Delta FosB regulates wheel running. J Neurosci 22: 8133-8138.

Wilson CJ, Kawaguchi Y (1996). The origins of two-state spontaneous membrane potential fluctuations of neostriatal spiny neurons. J Neurosci 16: 2397-2410.

Zhou D, Shearman LP (2004). Voluntary exercise augments acute effects of CB1-receptor inverse agonist on body weight loss in obese and lean mice. Pharmacol Biochem Behav 77: 117-125. 